\title{
Neurocan developmental expression and function during early avian embryogenesis
}

\author{
Katerina Georgadaki and Nikolas Zagris*
}

*Correspondence: zagris@upatras.gr

CrossMark

- Click for updates

Division of Genetics and Cell and Developmental Biology, Department of Biology, University of Patras, Patras, Greece.

\begin{abstract}
Background: Neurocan is the most abundant lectican considered to be expressed exclusively in the central nervous system. Neurocan interacts with other matrix components, with cell adhesion molecules, growth factors, enzymes and cell surface receptors. The interaction repertoire and evidence from cellular studies indicated an active role in signal transduction and major cellular programs. Relatively little is known about the neurocan tissue-specific distribution and function during embryonic development. This study examined the time of appearance and subsequent spatio-temporal expression pattern of neurocan and its functional activities during the earliest stages of development in the chick embryo.

Methods: To detect the first expression and spatio-temporal distribution of neurocan in the early embryo, strand- specific reverse transcription-polymerase chain reaction (RT-PCR), immunoprecipitation and immunofluorescence were performed. An anti-neurocan blocking antibody transient pulse was applied to embryos at the onset of the neurula stage to perturb neurocan activities in the background of the current cellular signaling state of the developing embryo.

Results: Neurocan was first detected in the inchoate neural plate and the extracellular matrix in embryos at the definitive streak stage (late gastrula). During early organogenesis, neurocan fluorescence was very intense in the neural tube, notochord, neural crest cells, pharyngeal arches, foregut lower wall, presumptive pronephric tubules, blood islands, dorsal mesocardium, intense in myocardium and distinct in endocardium, very intense in the presumptive cornea and intense in retina and lens, intense in somite and nephrotome. Antibody perturbation of neurocan function resulted in three predominant defects: (1) abnormal expansion of neuroepithelium in the surface ectoderm flanking the neural tube; (2) neural crest cells formed epithelial pockets located on the ectoderm apical surface; and (3) surface ectoderm cells (presumptive epidermis) acquired mesenchymal cell properties, invaded into the subectodermal space and interacted with neuroectoderm.
\end{abstract}

Conclusions: Neurocan was first expressed in the inchoate neural plate at the late gastrula stage. Neurocan expression was very intense in the developing central nervous system as well as in many non-neural tissues. Neurocan seems to modulate signalling in the neural-non-neural tissue specification and the adhesive and signalling activities of epithelial-mesenchymal cells and neural crest cell motility in the early embryo.

Keywords: Cell adhesion, growth factors, neural-non-neural specification, neural crest, tenascin, hyaluronan, morphogenesis

\section{Background}

Neurocan is a member of the lecticans, a structurally similar chondroitin sulfate proteoglycan family, which includes aggrecan, versican and brevican [1-3]. Neurocan has been identified by molecular cloning in the brain and was considered to be a brain-specific chondroitin sulfate proteoglycan [4-6].
Subsequent work reported that neurocan was also detected in the endocardium of 4-day-old chick embryos [7], in the embryonic heart and vasculature in quail embryos at the $\mathrm{HH}$ (Hamburger and Hamilton) stage 11 (13 somites) [8], and in mouse lymphoid cells [9] and mammary tumors [10]. Both the carbohydrate side chains and the polypeptide backbone of 
neurocan interact with the cell adhesion molecules $\mathrm{Ng}$-CAM/ L1 (neuron glia-cell adhesion molecule), axonin, and N-CAM (neural cell adhesion molecule) $[11,12]$. Through the interaction with cell surface GalNAcPTase ( $\mathrm{N}$-acetylgalactosaminyl phosphotransferase), neurocan regulates $\mathrm{N}$-cadherin and $\beta 1$ integrin function co-ordinately $[13,14]$. Neurocan interacts with other extracellular matrix molecules, such as heparin, tenascins $[3,15,16]$ and with growth factors and cytokines FGF-2, HB-GAM (heparin-binding growth-associated molecule), and amphoterin $[3,17]$. The neurocan $\mathrm{N}$-terminal domain interacts with hyaluronan through the link proteins and the C-type lectin neurocan C-terminal domain interacts with sulfatides, and sulfated cell surface glycolipids. The wide range of interactions enable neurocan to participate in a network consisting of tenascin-hyaluronan and cell surface receptors $[2,3,18]$.

Many studies have emphasized that the interaction repertoire of neurocan through distinct domains and the evidence from cellular studies suggest that neurocan has evolved as an modular extracellular regulator of cell-cell and cell-matrix interactions that guide the cellular rearrangements essential to the formation and function of the nervous system $[1-3,13]$.

Neurocan knockout mice [19] showed only some behavioural abnormalities without visible abnormal anatomical features. There are a number of developmentally significant genes, such as tenascin, that on targeted disruption show mild mutations or no observably aberrant phenotypes [20-22]. The apparent dispensability of tenascin, neurocan or of other genes during development was interpreted in a number of interesting ways $[19,21,23,24]$. As has been well stated [21,23-26], cautious interpretation should be exercised when examining the effects of gene deletions in view of the large number of variables that can operate during embryogenesis, the existence of compensatory mechanisms during regulative development, and the pleiotropy and variable penetrance resulting from mutation or deletion of a single gene. Zimmermann and Dours-Zimmermann [25] remarked that although the highest matrix protein expression in the central nervous system during early neural development has been attributed to tenascin and neurocan, their in vivo functions in the juvenile-type of matrix are still largely unknown.

Most studies with neurocan have been conducted in rat and mouse, mainly in the late embryonic stages, in postnatal development and the adult and in cell cultures. The neurocan function is elusive $[4-8,25]$. In vitro studies have shown that neurocan is able to modulate cell-binding, axon guidance and synapse formation during the development of the nervous system via adhesion molecules $[3,11,13,27]$. Despite the great amount of information available on the structural and biochemical features and the interactions of neurocan with other molecules, relatively little is known about the neurocan expression and function in the early embryo. In our present work, we studied how early neurocan is expressed and present a detailed developmental profile of the neurocan expression pattern in the chick embryo from stage $X$ (homologous to the morula in amphibia), when the embryo is histologically simple, to the early stages of organogenesis (stage $\mathrm{HH} 17,29$ somites). We then used blocking antibodies directed against neurocan to perturb neurocan activities when neurocan is first detected in embryos at the onset of the neurula stage.

\section{Methods \\ Animal studies}

Fertilized chicken eggs (supplied by the Epirus Poultry Co., loannina, Greece) were incubated at $37.5^{\circ} \mathrm{C}$ under high humidity. The chick embryo studies and all procedures were preformed in accordance with the guidelines of the National Ethical Commission for Animal Research (Ministry of Education, Greece) and the Institutional Animal Care and Use Committee (University of Patras).

\section{RT-PCR}

The presence of neurocan mRNA at various stages of the early chick embryo was assessed by PCR amplification from mRNA derived cDNA. Total RNA was prepared (RNeasy Mini Kit protocol, Qiagen) from chick embryos at stages XI (morula), XIII (late blastula), $\mathrm{HH} 2$ (initial streak/early gastrula), $\mathrm{HH} 3$ (intermediate streak), $\mathrm{HH} 4-5$ (definitive streak to head process) and $\mathrm{HH} 6$ (head fold). Attention was paid to the exact developmental stage of the embryos according to Hamburger and Hamilton (HH symbol) [28]. PCR primers were 5'-ACA CCA GCA ACA GCA GCC AGC-3' (sense, position 2955) and 5'-GCA GAT GTA GGG CAG GTT GTA G-3' (antisense, position 3561) specific for a fragment of 607-bp (from 2955 to 3561) of quail neurocan mRNA. For $\beta$-actin, a fragment of 187 -bp was amplified with the following primers: sense $5^{\prime}-\mathrm{CGG}$ TAT TGT CAC CAA CTG G-3' and antisense 5'-TGG CTA CAT ACA TGG CTG G-3' were used in a parallel reaction as the neurocan primers. The quail neurocan $[\mathbf{8}]$ and chick $\beta$-actin $[\mathbf{2 9}, \mathbf{3 0}]$ primers were the same as those published previously. Single stranded cDNA was synthesized employing as template $2 \mu \mathrm{g}$ of total RNA from embryos according to the manufacturer OneStep RT-PCR Kit protocol (Qiagen); the RNA was omitted from the reaction in the negative control samples. Amplification conditions were started at $95^{\circ} \mathrm{C}$ for $15 \mathrm{~min}$, and then subjected to 35 and 31 cycles for neurocan and $\beta$-actin, respectively, of [denaturation $94^{\circ} \mathrm{C}$ for $30 \mathrm{sec}$, annealing $65^{\circ} \mathrm{C}\left(55^{\circ} \mathrm{C}\right.$ for $\beta$-actin) for $1 \mathrm{~min}$, elongation $72^{\circ} \mathrm{C}$ for $1 \mathrm{~min}$ ], and one cycle of extension $72^{\circ} \mathrm{C}$ for $10 \mathrm{~min}$. PCR amplification products $(5 \mu \mathrm{l} /$ lane and $3 \mu \mathrm{l} /$ lane for neurocan and $\beta$-actin, respectively) were separated on a $5 \%$ polyacrylamide gel and stained with ethidium bromide. A 100-10,000bp ladder was used as a marker (GeneRuler DNA Ladder Mix, Fermentas). The bands were quantified by a laser scanning densitometry and computer integration (Scion Image PC). The values were normalized to the $\beta$-actin transcript level.

\section{Neurocan Immunoprecipitation}

Neurocan was identified from chick embryos by immuno- 
precipitation of material with an anti-neurocan monoclonal antibody (clone 1F6) and analysis by SDS-polyacrylamide gel electrophoresis (SDS-PAGE). The monoclonal antibody (clone 1F6) that recognizes an epitope (N-terminal epitope) on the core protein of neurocan [31] was obtained from the Developmental Studies Hybridoma Bank (University of lowa, lowa City, IA, USA).

Embryos at stages $\mathrm{HH} 5$ (head process) to $\mathrm{HH} 8$ (5-somites) (78 embryos) were solubilized in $400 \mu$ l lysing buffer [1\% (v/v) Triton X-100, $0.02 \mathrm{M} \mathrm{NaCl}, 0.002 \mathrm{M}$ ethylenediamine tetraacetic acid (EDTA), $0.004 \mathrm{M}$ ethylene glycol bis(2-aminoethylether)$\mathrm{N}, \mathrm{N}^{\prime}$-tetraacetic acid (EGTA), $0.04 \mathrm{M}$ tris(hydroxymethyl) aminomethane hydrochloride (Tris-HCl), pH 7.5] containing $0.7 \mu \mathrm{g} / \mathrm{ml}$ pepstatin and $40 \mu \mathrm{g} / \mathrm{ml}$ phenylmethanesulfonyl fluoride (PMSF). Nuclei and insoluble material were pelleted by centrifugation for $5 \mathrm{~min}$ at 13,000 rpm. The supernatant $(400 \mu l)$ was mixed with immunoprecipitation buffer $[0.05 \%$ (v/v) NP-40, $0.05 \mathrm{M} \mathrm{NaCl}, 0.0029 \mathrm{M}$ EGTA, $0.01 \mathrm{M}$ Tris- $\mathrm{HCl}, \mathrm{pH}$ 7.4] (1:6 dilution) and was split into two equal aliquots, each containing the equivalent homogenate from 39 embryos. The one aliquot reacted with the preformed neurocan antibodyprotein A-Sepharose complex (experimental) while the other reacted with the preformed mouse IgG-protein A-Sepharose complex (control) by mild agitation.

Protein A-Sepharose CL-4B (5mg, Sigma Chemical, St Louis, Mo., USA) was suspended in Tris- $\mathrm{NaCl}$ buffer $(0.15 \mathrm{M} \mathrm{NaCl}$ $0.05 \mathrm{M}$ Tris- $\mathrm{HCl}, \mathrm{pH} 8.5$ ) by agitation for $10 \mathrm{~min}$ and washed 5 times in the same buffer. The neurocan monoclonal antibody described above $(200 \mu \mathrm{l})$ or the mouse lgG that served as the negative control were diluted with Tris- $\mathrm{NaCl}$ buffer (1:4 dilution) and were added to the protein A-Sepharose pellet. Sepharose was suspended by mild agitation and the antibody-protein A-Sepharose complex was allowed to form for at least $2 \mathrm{~h}$ at room temperature. Sepharose was washed 3 times with Tris- $\mathrm{NaCl}$ buffer and 2 times with immunoprecipitation buffer.

After addition of the one supernatant aliquot to the preformed neurocan antibody-protein A-Sepharose complex and the other supernatant aliquot to the preformed mouse IgG-protein A-Sepharose complex, the immune complex was allowed to form overnight at $4^{\circ} \mathrm{C}$ with end-over-end mixing. The resins (precipitates) were removed after centrifugation, washed 10 times with immunoprecipitation buffer. Chondroitinase ABC from Proteus vulgaris (1 unit/mg proteoglycan) (Seikagaku co. Tokyo, Japan), an enzyme digesting the glycosaminoglycan side chains of chondroitin sulfate proteoglycans, $0.1 \mathrm{M}$ Tris- $\mathrm{HCl}$ and $0.4 \mathrm{mM} \mathrm{PMSF}$ was added to the pellet and incubated overnight at $37^{\circ} \mathrm{C}$. At the end of the incubation, the mixture was centrifuged at 10,000 rpm for 4 $\mathrm{min}$ and the material bound to the resins was dissociated by boiling for $2 \mathrm{~min}$ in electrophoresis sample buffer containing $10 \% \beta$-mercapto-ethanol [32]. The immunoprecipitates were analyzed in 5\% slab SDS-PAGE [32] and stained with Coomassie brilliant blue. Molecular mass of identified polypeptides was determined according to electrophoretic migration of standard markers (Rainbow markers, Amersham Biosciences, Piscataway, N.J., USA).

\section{Neurocan immunolabeling}

Chick embryos at stages X (morula), XIII (late blastula), HH34 (intermediate to definitive streak), $\mathrm{HH} 4$ (definitive streak), $\mathrm{HH} 13$ (19-somites) and HH17 (29-somites, $52 \mathrm{~h}$ of development) were removed from their eggs and adhering yolk was cleaned off with fine dissecting needles. The embryos were flattened either dorsal (epiblast)- or ventral (hypoblast)side against the surface of vitelline membrane rafts [33] to establish a firm support during fixation. The embryos were subsequently fixed in Carnoy fixative (formula B) [34], were dehydrated through graded ethanol solutions, embedded in paraffin and sectioned $(7 \mu \mathrm{m})$ serially.

Serial sections from embryos at the stages described above were used. Immunolabeling was preformed as described previously [35]. The monoclonal anti-neurocan antibody (clone 1F6) was used at a final concentration of $10 \mu \mathrm{g} / \mathrm{ml}$ in PBS and the sections were incubated overnight at $37.5^{\circ} \mathrm{C}$ in a moist chamber. The fluorescein-conjugated goat anti-mouse IgG secondary antibody (Santa Cruz Biotech., USA) was used at a final concentration of $5 \mu \mathrm{g} / \mathrm{ml}$ in PBS for $1 \mathrm{~h}$ at $37.5^{\circ} \mathrm{C}$ in a moist chamber. The sections were rinsed 3 times $(20 \mathrm{~min}$ each) in PBS and mounted in glycerol-Mowiol 4-88. Sections were observed and photographed (magnification powers 20, 40 and 100X) with epifluorescent illumination, using filters selective for fluorescein. For control slides, primary antibody was omitted and sections were incubated with mouse IgG and with fluoresceinated secondary antibody.

\section{Function-blocking neurocan antibodies}

Embryos at stage $\mathrm{HH} 4$ (definitive streak) were removed from their eggs, cleaned of adhering yolk, were placed in $400 \mu \mathrm{l}$ Ringer solution containing the monoclonal anti-neurocan antibody $1 \mathrm{~F} 6(1 \mu \mathrm{g} / \mathrm{ml}$ final concentration) in a microwell (G20 Culture slide; Arthur Thomas, Philadelphia, Pa., USA) and incubated for $2 \mathrm{~h}$ at $37.5^{\circ} \mathrm{C}$. The antibody was used at $1 \mu \mathrm{g} / \mathrm{ml}$ final concentration because it was the concentration which produced consistent results. At the end of the incubation period, the embryos were washed in Ringer solution, flattened with their epiblast side against the surface of vitelline membrane support rafts [33] and cultured on plain egg albumen at $37.5^{\circ} \mathrm{C}$. Embryos incubated in plain Ringer solution or in Ringer solution containing mouse IgG, then cultured on plain egg albumen in a parallel culture, served as controls. Embryos were photographed after $22 \mathrm{~h}$ in culture, fixed in Carnoy fixative, dehydrated, embedded in paraffin and sectioned $(7 \mu \mathrm{m})$ serially. Sections were deparaffinized and stained in Alcian blue 8GX (stains both sulfated and non-sulfated proteoglycans; Sigma, St. Louis, Mo., USA) and counterstained with Nuclear fast red (stains nuclei; Sigma, St. Louis, Mo., USA) (Alcian blue method, pH 2.5) [34].

Thirty five embryos ( 10 control, 25 experimental) were used 
in the course of this investigation. Seven embryos, usually five experimental and two control, were cultured per experiment. Embryos, cultured media and glassware were handled under sterile conditions.

\section{Results}

Expression of the neurocan gene in the early embryo In our present work, RT-PCR was preformed to determine the developmental expression of the neurocan gene in the early chick embryo. Total RNA was isolated from chick embryos at stages XI (morula), XIII (late blastula), HH2 (initial streak/early gastrula), $\mathrm{HH} 3$ (intermediate streak), $\mathrm{HH} 4-5$ (definitive streak to head process) and $\mathrm{HH} 6$ (head fold) (Figure 1). The results showed bands of the predicted size of $607 \mathrm{bp}$ for neurocan and $187 \mathrm{bp}$ for $\beta$-actin (Figure 1); no products were observed if RNA was omitted from the reaction. We did not detect the predicted 607-bp PCR product in neurocan cDNA derived from embryos at stages XI and XIII (not shown), HH2 and HH3 (Figure 1). Neurocan mRNA was detected in stage HH4-5 embryos and continued to be expressed later in development (Figure 1).

\section{Neurocan immunoprecipitation}

Embryos at stages $\mathrm{HH} 5$ to $\mathrm{HH} 8$ were extracted with EDTA-

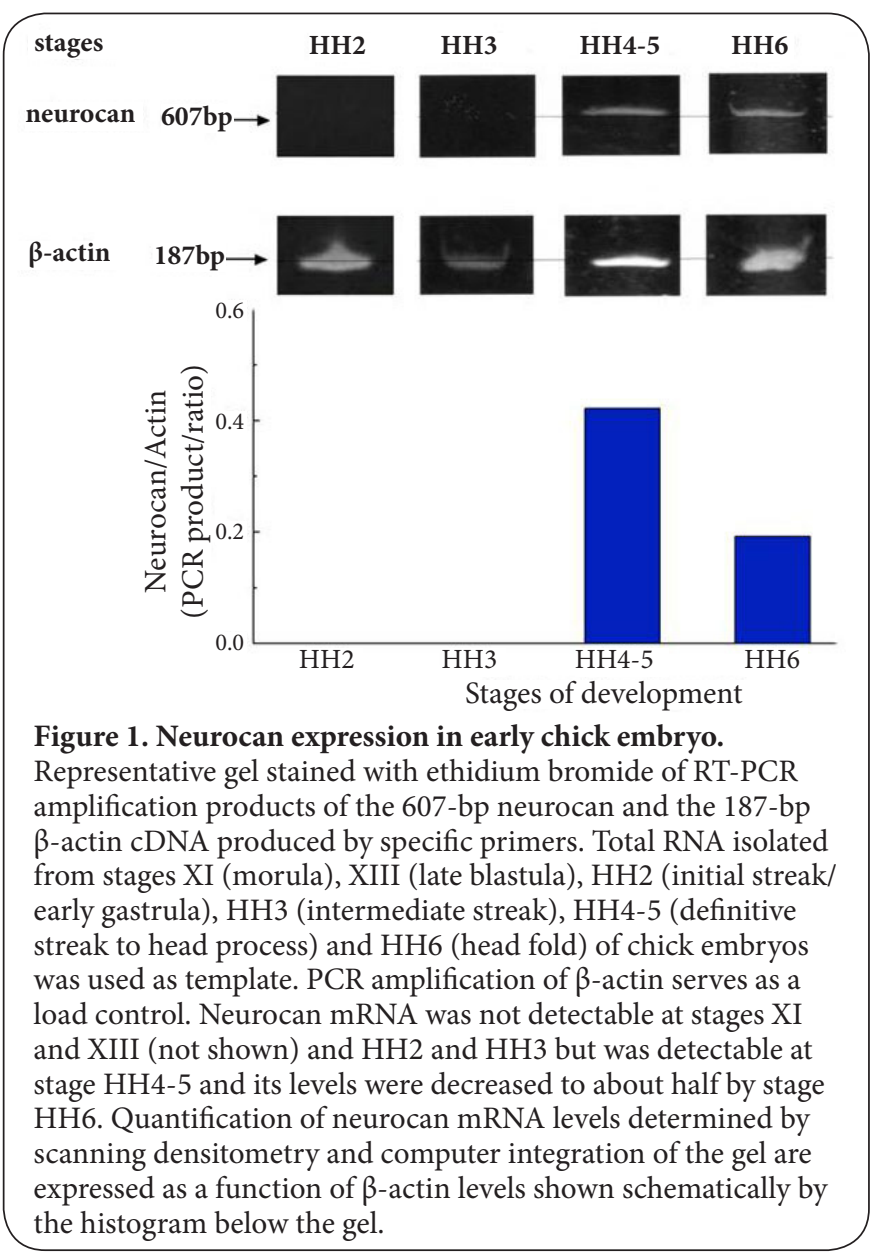

containing buffer and were subjected to an antibody affinity column specific for the neurocan core protein. The immunoprecipitates were separated by SDS-PAGE slab gel. As shown in Figure 2, the anti-neurocan monoclonal antibody (clone 1F6) immunoprecipitated a protein migrating with a relative molecular mass at approximately $245 \mathrm{kDa}$ (lane a). This band was absent in immunoprecipitations with preimmune serum (lane b) and is therefore likely to correspond to the chick neurocan. Molecular mass of identified polypeptides was determined according to electrophoretic migration of standards.

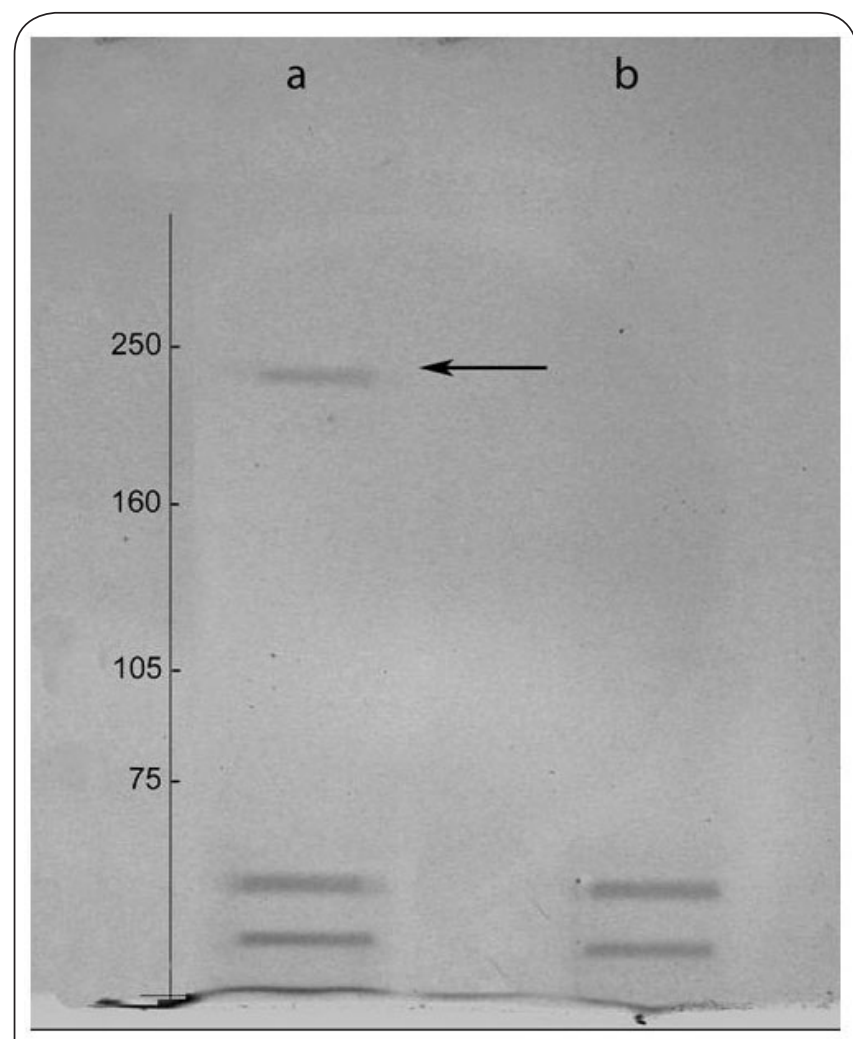

Figure 2. Immunoprecipitation of neurocan isolated from early chick embryos.

Embryos at stages HH5 (head process) to HH8 (5-somites) were precipitated either with monoclonal IgG directed at neurocan (lane a) or with nonimmune mouse IgG (lane b). Precipitates were analyzed in 5\% slab SDS-PAGE and stained with Coomassie brilliant blue. The anti-neurocan monoclonal antibody (clone 1F6) recognized a band at molecular mass of approximately $245 \mathrm{kDa}$ (lane a, arrow) not recognized by the nonimmune mouse IgG and it is likely to correspond to chick neurocan. Numbers to the left refer to the migration of molecular mass protein markers in kilodaltons.

\section{Spatio-temporal patterns of neurocan}

Neurocan expression pattern in very early embryos Immunofluorescence analysis showed the spatial and temporal distribution of neurocan from stage $X$ (morula) up to stage HH17 (29 somites) in the chick embryo. Immunofluorescence 
staining was preformed using the 1F6 monoclonal antibody that recognizes the neurocan $\mathrm{N}$-terminal specific epitope [31]. Neurocan protein was not detected in embryos at stages $X$ (morula) (not shown), XIII (late blastula) (Figure 3A) and HH34 (intermediate to definitive streak) (Figure 3B). The earliest expression of neurocan was intense in the inchoate neural plate and in the extracellular matrix at stage $\mathrm{HH} 4$ (definitive streak) (Figure 3C) in agreement with the timing of neurocan mRNA expression. Neurocan was sparse in mesoderm and endoderm and virtually undetectable in ectoderm at this stage.

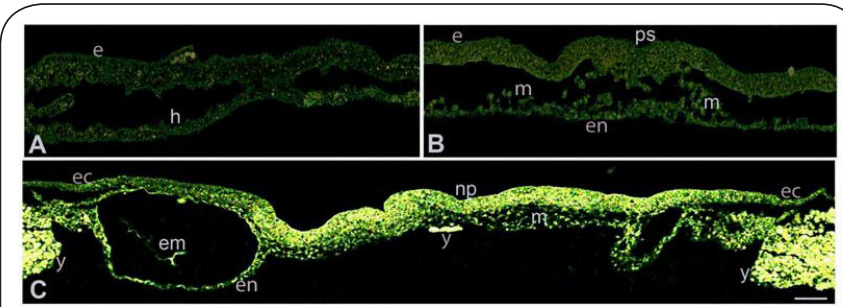

Figure 3. Neurocan immunolocalization in early chick embryos shown on transverse sections.

$(\mathbf{A}, \mathbf{B})$ neurocan was undetectable in embryos at stages XIII (late blastula) (A) and $\mathrm{HH}$-4 (intermediate streak to definitive streak) (B). (C) Neurocan immunoreactivity was intense in the inchoate neural plate $(n p)$ and distinct in the extracellular matrix $(\mathrm{em})$ in embryos at stage $\mathrm{HH} 4$ (definitive streak). e: epiblast; ec: ectoderm; en: endoderm; h: hypoblast; m: mesoderm; ps: primitive streak; y: yolk-laden cell. Scale bar $50 \mu \mathrm{m}$.

\section{Neurocan expression pattern in 19-somite embryos}

At the 19-somite stage ( $\mathrm{HH} 13)$, neurocan was widely expressed with very intense localization to the myelencephalon and notochord (Figure 4A); of note, the prominent neurocan localization in an organized extracellular matrix in the myelencephalon lumen (Figure 4A) shown under higher magnification in Figure 4B. Note the very intense neurocan fluorescence in the cells streaming out of the neural crest and in the migrating neural crest cells underlying the ectoderm and inserted in the periaortic region and in the gut lateral and lower wall. Higher magnification image of neural crest cells emerging from the myelencephalon and starting to migrate showed intense neurocan fluorescence localized in the main body and along the elongated filopodial protrusions of these cells (Figure 4E). In the developing heart, neurocan was very intense in the dorsal mesocardium and intense in the myocardium and weakly intense in the single layered endocardium (Figure 4A).

A section through the pharyngeal arch region of the same embryo revealed neurocan was very intense in the myelencephalon, notochord and the premigratory and also the migrating neural crest cells (Figure 4C). Figure 4D showed a higher magnification image of the cells that emerge from the neural crest and start their migration in a broad wave. Note the neurocan intensity in the mesenchymal cells, known to be derived from the neural crest, underlying the ectoderm

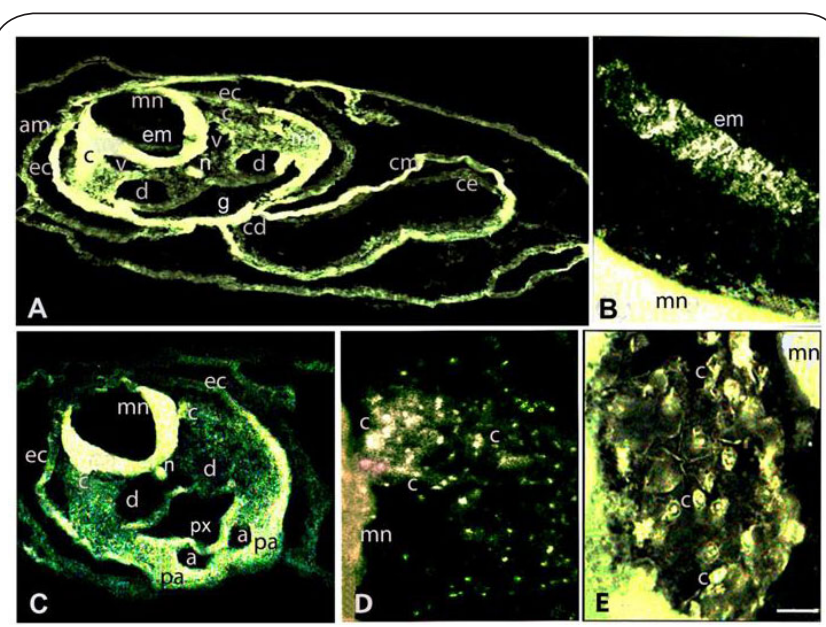

Figure 4. Neurocan immunolocalization in chick embryo at stage HH13 (19 somites).

Transverse sections at the heart (A) and pharyngeal arch (C) levels. (A) Neurocan immunoreactivity was intense in myelencephalon $(m n)$, notochord $(n)$, pre-migratory and in migrating neural crest cells $(c)$ underlying the ectoderm and inserted in the periaortic region and the gut $(g)$ lateral and lower wall, dorsal aorta $(d)$ and common cardinal vein $(v)$, in dorsal mesocardium $(c d)$ and was strong in myocardium $(\mathrm{cm})$ and endocardium $(\mathrm{ce})$ and in extracellular matrix $(\mathrm{em})$ in myelencephalon lumen; (B) intense neurocan localization in an organized extracellular matrix in myelencephalon lumen shown in (A) presented under higher magnification. (C) At the pharyngeal arch level of the same embryo, neurocan immunoreactivity was intense in myelencephalon $(\mathrm{mn})$, notochord $(n)$, and the premigratory and migratory neural crest cells $(c)$ underlying the ectoderm $(e c)$ and colonizing the pharynx $(p x)$ lateral and lower wall and the pharyngeal $(p a)$ and aortic ( $a$ ) arches; (D) distinct neurocan fluorescence in neural crest cells emerging from the myelencephalon as shown in (C) start their migration as a broad wave presented at higher magnification. (E) Neural crest cells emerging from the myelencephalon and migrating shown in embryonic section (A) display intense neurocan fluorescence in the main body and filopodial protrusions presented at higher magnification. am: amnion. Scale bar $50 \mu \mathrm{m}$ in $(\mathbf{A}, \mathbf{C}), 25 \mu \mathrm{m}$ in (D) and $10 \mu \mathrm{m}$ in $(\mathbf{B}, \mathbf{E})$.

during their migration and colonization into the pharyngeal and aortic arches.

\section{Neurocan expression pattern in 29-somite embryos}

By the 29-somite stage ( $\mathrm{HH} 17)$, neurocan was very intense in the telencephalon, diencephalon and myelencephalon and the neural tube (Figure 5). Note the neurocan intensity in the infundibulum (elongation of the diencephalon) and the Rathke's pouch (continuous with stomodeum) as they interact to form the pituitary (Figure 5A). Cranial neural crest cells exhibited intense neurocan fluorescence; a population of these cells migrates into the eye and participates in the development of the cornea and also into the nasal placode. Neurocan fluorescence was intense and was distributed almost 
uniformly throughout the sensory and pigmented retina and the lens (Figure $\mathbf{5 A}$ ). Of note, the neurocan intensity in the ectoderm (presumptive cornea) that interacts with the lens and will give rise to the cornea but neurocan fluorescence was virtually undetectable in the ectoderm lateral to the presumptive cornea (Figures 5A and 5D). Neurocan fluorescence was very intense in the notochord periphery, in the first ganglion formed from neural crest cells, and in the nasal placode, pharynx, pharyngeal and aortic arches, tissues populated predominantly by neural crest cells (Figures 5A and 5B).

A section at the heart level (Figure 5B), revealed neurocan fluorescence very intense in the head mesenchyme that will give rise to the skull bones, very intense in dorsal aorta and the mesenchyme in the periaortic region, in the pharynx and was distinct in the extracellular matrix in the brain and pharynx lumen (Figures 5A and 5B). Neurocan was very intense

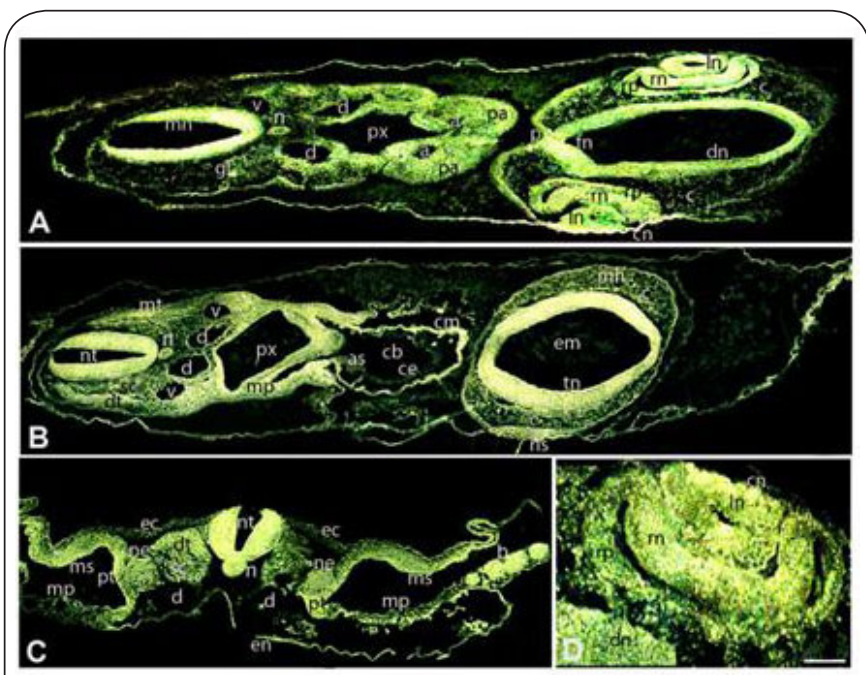

Figure 5. Neurocan immunolocalization in chick embryo at stage HH17 (29 somites).

Transverse sections at the eye (A), heart (B) and trunk (C) levels. (A,B) Neurocan immunoreactivity was intense in telencephalon $(t n)$, diencephalon $(d n)$, myelencephalon $(m n)$, neural tube $(n t)$, infundibulum $(f n)$ and Rathke's pouch $(p)$, the notochord $(n)$ periphery, the sympathetic neural ganglia $(g l)$, neural crest cells $(c)$ and head mesenchyme $(m h)$, nasal placode $(n s)$, the lens $(l n)$ and presumptive cornea $(c n)$, neural $(r n)$ and pigmented $(r p)$ retina, myocardium $(\mathrm{cm})$ and endocardium $(c e)$ of bulbus cordis $(c b)$, intense in myotome $(m t)$ and strong in sclerotome $(s c)$, intense in dorsal aorta $(d)$ and common cardinal vein $(v)$ and periaortic mesenchyme, in pharynx $(p x)$ and in the splanchnic mesoderm $(m p)$ lining the pharynx, and was distinct in extracellular matrix $(\mathrm{em})$ in pharynx and brain lumen. (C) At the trunk region, neurocan was intense in the neural tube $(n t)$, notochord $(n)$, strong in dermamyotome $(d t)$ and distinct in sclerotome $(s c)$, strong in nephrotome (ne) and intense in presumptive pronephric tubules $(p t)$, strong in lateral somatic mesoderm ( $m s)$, intense in blood islands $(b)$ and strong in endoderm (en). (D) Higher magnification image of the eye from embryonic section neighboring the embryonic section in (A). as: aortic sac; ec: ectoderm; mp: splanchnic mesoderm. Scale bar $50 \mu \mathrm{m}$ in (A-C) and $25 \mu \mathrm{m}$ in (D). in the myotome, intense in the migrating sclerotomal cells in somites and was intense in the myocardium and of weak intensity in the single layered endocardium (Figure 5B).

In the trunk region of the same embryo (Figure $5 \mathrm{C}$ ), neurocan fluorescence was very intense in the neural tube, notochord and the blood islands. The epithelialized somites showed neurocan fluorescence intense in the dermomyotome and sclerotome. Neurocan was intense in the nephrotome and was very intense in the adjacent lateral mesoderm that will form pronephric tubules and was also intense in the more lateral somatic but not the splanchnic mesoderm.

\section{Functional role of neurocan}

We used anti-neurocan blocking antibodies to perturb neurocan-depended cell adhesion and signalling programs when neurocan is first detected at the onset of the neurula stage. Embryos exposed to anti-neurocan antibodies at the definitive streak stage $(\mathrm{HH} 4)$ showed abnormalities along the craniocaudal axis (Figure 6a) compared to matched control embryos (Figure $6 \mathbf{b}$ ) after about $22 \mathrm{hr}$ of culture. As can be seen at a gross morphological level, the developing neural tube at the cephalic region seemed perturbed, the notochord seemed fragmented and the paraxial mesoderm flanking the notochord did not show the characteristic thick band morphology but appeared diffuse and disorganized in the embryos exposed to the antibody (Figure 6 a). In reading serial transverse sections of the experimental embryo in Figure 6a, note that neural crest cells formed epithelial pockets located on the apical surface of the ectoderm shown in 2-adjacent sections (Figures 6A and $6 \mathrm{~B}$ ) in the cephalic region. Higher magnification images of regions in Figures $6 \mathrm{~A}$ and $6 \mathrm{~B}$ are shown in Figures $6 \mathrm{~K}$ and $6 \mathrm{~L}-6 \mathrm{M}$, respectively.

Curiously, surface ectoderm cells (presumptive epidermis) dissociated from the epithelium, adopted a fibroblastoid phenotype and acquired invasive and migratory properties; Figures 6D-6F showed ectoderm cells transverse basement membranes, invaded into the subectodermal space and interacted with neural tube cells. Higher magnification images of regions in Figures $6 \mathrm{E}$ and $6 \mathrm{~F}$ are shown in Figures 60 and $6 \mathrm{P}$, respectively. Figures $6 \mathrm{D}-6 \mathrm{~F}$ showed 3 -adjacent transverse sections $119 \mu \mathrm{m}$ (17 sections) posterior to the section in Figure 6B.

More posterior serial sections showed the abnormal expansion of neuroepithelium in the surface ectoderm (presumptive epidermis) flanking the neural tube (Figures 6G-6I). Note that these cells showed the typical thickened, pseudostratified neuroepithelium morphology very similar to the neural tube and that they interacted with the cells of the neural tube. In the cephalic region, note abnormal neuroepithelium aggregates clustered to the neural tube lateral surface in Figures $6 \mathrm{~A}-6 \mathrm{C}$. Figure $6 \mathrm{C}$ is $14 \mu \mathrm{m}$ ( 2 sections) to the posterior of section in Figure 6B. Higher magnification images of regions in Figures $6 \mathrm{~B}$, $6 \mathrm{C}, 6 \mathrm{G}$ and $6 \mathrm{I}$ are shown in Figures $6 \mathrm{M}, 6 \mathrm{~N}, 6 \mathrm{Q}$ and $6 \mathrm{R}$, respectively. Figures $\mathbf{6 G - 6 I}$ showed 3 -adjacent transverse sections $28 \mu \mathrm{m}$ ( 4 sections) posterior to the section in Figure $6 \mathrm{~F}$. 


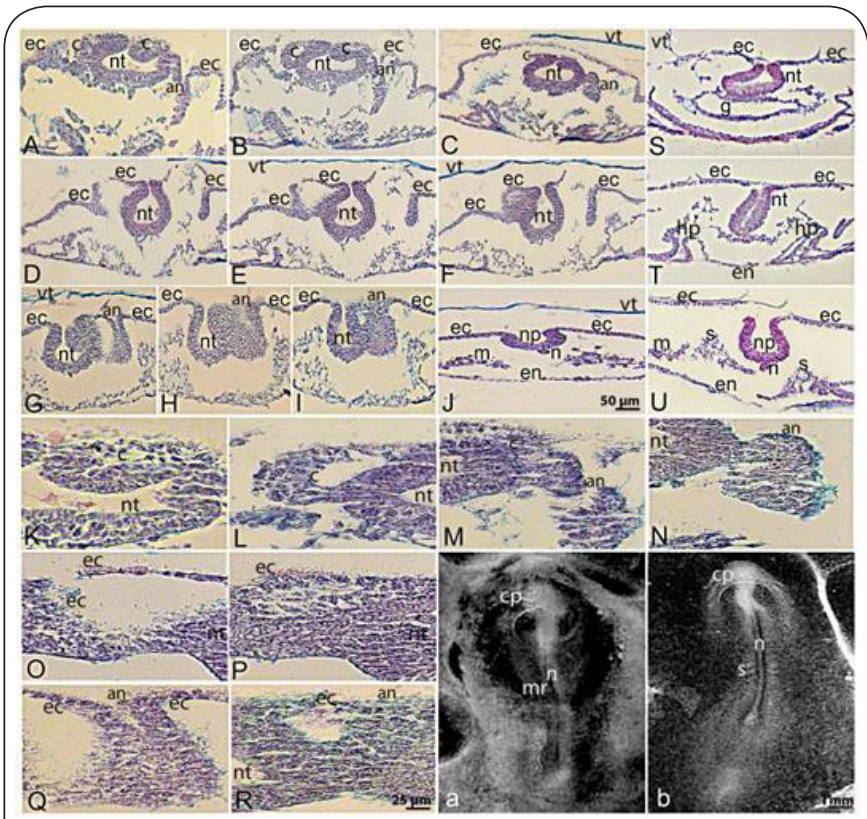

Figure 6. Neurocan modulates signaling in neural-nonneural specification, adhesion and neural crest motility. Embryos at stage HH4 (definitive streak) were exposed either to monoclonal IgG directed at neurocan (experimental) or plain Ringer solution (control) for $2 \mathrm{~h}$ then cultured on plain egg albumen for 22h. (a) Experimental embryo formed an embryonic axis but the cephalic region seemed perturbed, the notochord fragmented and the paraxial mesoderm appeared diffuse and disorganized compared to control embryo in (b). $(\mathbf{A}-\mathbf{R})$ and $(\mathbf{S}-\mathbf{U})$ are transverse sections of the embryos in (a) and in (b), respectively. (A-C) Adjacent sections through the cephalic region $(c p)$ of the neural tube showed the neural crest $(c)$ formed epithelial pockets located on the apical surface of the ectoderm $(e c)$. (D-F) Consecutive sections showed surface ectoderm (presumptive epidermis) (ec) transverse basement membranes, invaded into the subectodermal space and interacted with neural tube ( $n t)$ cells. (G-I) Adjacent sections showed abnormal expansion of neuroepithelium $(a n)$ in the surface ectoderm (ec) flanking the neural tube. (J) Transverse section through the somite level showed paraxial mesoderm $(m)$ diffuse. (K,L-M,N) High magnification images of the neural crest $(c)$ epithelial pockets and aggregates shown in $(\mathbf{A}-\mathbf{C})$, respectively. $(\mathbf{O}, \mathbf{P})$ High magnification images of surface ectoderm $(e c)$ invasion into the subectodermal space and interaction with neural tube $(n t)$ cells shown in $(\mathbf{E}, \mathbf{F})$, respectively. (Q,R) High magnification images of $(\mathbf{G}, \mathbf{I})$, respectively, showed abnormal expansion of neuroepithelium (an) flanking and interacting with the neural tube. (S-U) Transverse sections at the cephalic (S), heart primordia (T) and somite levels (U) of control embryo in (b). Transverse sections $(7 \mu \mathrm{m})$ stained with Alcian blue and nuclear fast red. cp: cephalic region; ec: ectoderm; en: endoderm; g: gut; hp: heart primordia; m: mesoderm; mr: paraxial mesoderm; n: notochord; np: neural plate; nt: neural tube; s: somite; vt: vitelline membrane. Scale bar $1 \mathrm{~mm}$ in embryos (a,b), $50 \mu \mathrm{m}$ in $(\mathbf{A}-\mathbf{J})$ and $(\mathbf{S}-\mathbf{U}), 25 \mu \mathrm{m}$ in (K-R).

Sections through the somite region of the same embryo showed the neural plate, the notochord and diffuse mesoderm cells flanking the notochord instead of the thick band mor- phology characteristic of the paraxial mesoderm (Figure 6J).

The results were reproducible within the same experiment, within different experiments. However, five (5) of the embryos (20\%) of the experimental group were more perturbed compared to the embryo presented in Figure 6a. They showed an abnormally expanded flat neural plate which had not folded to form even the primary neural tube, and the notochord was defined but had not lost contact to the lateral mesoderm.

Transverse sections (Figures 6S-6U) through the cephalic $(\mathbf{S})$, heart primordia $(\mathbf{T})$ and somite $(\mathbf{U})$ regions of the control embryo presented in Figure $\mathbf{6} \mathbf{b}$ showed the characteristic normal neural tube, notochord, heart primordia, paraxial mesoderm and gut morphology.

\section{Discussion}

It has long been thought that neurocan is a nervous-specific molecule [1-6]. In view of this assumption, our present results that neurocan is localized in multiple organ systems during the earliest stages of morphogenesis of the developing embryo are interesting. This suggested that neurocan may have wider functions during early embryogenesis than have been previously recognized.

Previous studies have determined the expression pattern of neurocan in mammalian embryos at late embryonic stages (E13-19/Embryonic 13-19 day), in postnatal and adult tissues or have been limited to studying neurocan expression mainly in the development of the nervous system [1-6]. Northern analysis, in situ hybridization histochemistry and immunocytochemical studies have demonstrated that neurocan is distributed widely in pre- and postnatal neural but not in other tissues [1-6]. However, the intriguing observation was made that the 1D1 and 1F6- neurocan specific antibodies sometimes show reactivity also with structures other than nervous tissue such as skin, meninges or mesenchyme in embryos, and remarked that neurocan may be transiently expressed in other tissues during prenatal development [6]. This observation of non-neural tissue localization of neurocan in meninges, skin, and mesenchyme could point to neural crest cells, transient cell populations which form the meninges, the melanocytes which give rise to the pigment of the skin and hair, and supply mesenchyme to several other developing organs. Neurocan has also been reported to be expressed in the heart and vasculature of avian embryos $[7,8]$, and in mouse T lymphocytes [9] and neoplastic mammary glands [10].

Our present study presented new data on the time of the earliest expression of neurocan and novel neurocan distribution patterns in the developing tissues and organs, and provided the first evidence for a distinctive functional role of neurocan during early embryogenesis. Neurocan was first detected in the inchoate neural plate and the extracellular matrix in embryos at the late gastrula stage (definitive streak/stage $\mathrm{HH} 4$ ) (Figures 1 and $3 \mathrm{C}$ ). This indicated that neurocan does not participate in signalling events required for the formation of the primitive streak and the major cell migrations during 
the gastrula stage. However, the expression of neurocan at the onset of the neurula stage suggested a role for neurocan in primary neurulation which involves the specification of neuroectoderm, thickening of the neural plate and formation of the neural tube by bending of the neural plate. Neurocan binds tightly to growth factors and interacts with many distinct adhesion molecules and these properties of neurocan could play critical roles during neural-non-neural cell specification and the spatial segregation of cell types.

At early developmental stages, the expression of neurocan was very intense and distinctive in the neural tube (developing central nervous system), in neural crest cells and in mesenchymal tissues which are known to be derived from the neural crest (Figures 4 and $\mathbf{5}$ ). The localization of neurocan in the pharyngeal arches and pouches seems to represent the influx of neurocan expressing neural crest cells in these structures (Figures 4 and $\mathbf{5}$ ) where they will form the odontoblasts of the tooth primordia, the bones of the middle ear and jaw and will contribute to the formation of the thymus, thyroid and parathyroid glands [36,37]. A similar distribution of neurocan-positive mesenchymal cells of neural crest origin was observed in many other regions including the periocular, perinasal, and periaortic mesenchyme, aortic arches and the gut lateral and lower wall (Figures 4 and 5); some neural crest cells accumulated along the aorta will form the aortic plexuses and the adrenal medulla, while other crest cells migrate to the heart, lungs and gastrointestinal tract where they will form the sympathetic organ plexuses [36,37]. Neurocan expression was intense in the retina and lens and very intense in the adjacent ectoderm (presumptive cornea) that interacts with the lens to form the cornea of the eye (Figures 5A and 5D). Relevant to our findings are previous studies which showed that neurocan is expressed strongly in the developing retinal tissue and that the neurocan-hyaluronan complex is involved in cornea development through interactions with N-CAMs [27]. Moreover, neurocan was localized in several areas of active cell migration including the somatic mesoderm, the myotomal and sclerotomal cells of the dispersing somite, the nephrotome and presumptive pronephric tubules, the myocardium and the single-cell layered endocardium of the heart and the blood islands which are mesodermal cells giving rise to hematopoietic lineages involved in erythropoiesis and angiogenesis (Figures 4 and $\mathbf{5}$ ).

The neurocan expression in non-neural tissues appears to be confined to a window of early embryonic development as previous studies have failed to detect neurocan in non-neural tissues at late embryonic stages and postnatal. An intriguing possibility is that the neurocan localization in multiple organ systems during the earliest stages of morphogenesis is transient and may be related to neural crest cells migrating and colonizing the various developing organs. The neural crest is a transient embryonic structure as its cells undergo epithelial- to-mesenchymal transition to disperse along the anteroposterior embryonic axis, enter different tissues and differentiate to a prodigious number of cell types and structures. These include pigment cells, peripheral neurons and glia, Schwann cells and meninges, adrenal medulla, cells that form muscles, cartilage, skeleton and connective tissue of craniofacial structures, certain tissues associated with the eye, cells of the endocardium and conotruncal cushions of the heart, odontoblasts and mesenchyme of the pharyngeal arches, and ensheath each aortic arch-derived vessel.

Premigratory and migrating neural crest cells showed very intense neurocan fluorescence (Figures 4 and 5 ). Tenascin and hyaluronan are also prevalent in the vicinity of early migrating neural crest cells, particularly along the subepidermal space and in the pericellular matrix of migrating neural crest cells [38-42]. Neurocan can act as a molecular bridge linking tenascin and hyaluronan and form a ternary (hyaluronan-lecticantenascin) complex, the HLT complex, thereby assembling a highly organized lattice of hyaluronan in the intercellular spaces $[\mathbf{1 5}, \mathbf{4 3}, \mathbf{4 4}]$. Earlier work proposed that tenascin/cytotactin may play a guiding or modulatory role in neural crest cell movement $[39,40]$. Chondroitin sulfate proteoglycans including neurocan have properties that are known to inhibit cell adhesion [44]. It is possible that neural crest cells may purposely use the neurocan-containing HLT complex to maintain their loose associations during their migration and to define a destination. Support for this proposition comes from studies which showed that the HTL complex deposited on neuronal surfaces may be a highly repulsive barrier against approaching axon and dendrites [44]. The striking distribution of neurocan expression in neural crest cells colonizing multiple organ systems allows the speculation that neurocan may play critical roles to the spatial segregation of neural crest cells and to tissue patterning during organogenesis. The multiplicity of ligands with differing properties could provide a means by which neurocan can modulate various developmental processes during histogenesis.

To investigate the developmental significance of the neurocan expression pattern in the early embryo, we used blocking antibodies directed against neurocan in embryos at the onset of the neurula stage when neurocan was first detected to gain insight into the neurocan activities in the background of the current cellular signaling state. It was striking to note the abnormal expansion of neuroepithelium in the surface ectoderm (presumptive epidermis) flanking the neural tube when neurocan function was altered by the anti-neurocan blocking antibodies (Figures 6A-6C, 6G-6I, 6M, 6N, $6 \mathrm{Q}$ and $6 \mathrm{R}$ ). It is known that the ectoderm is induced to become epidermal tissue by binding bone morphogenetic proteins (BMPs) while ongoing fibroblast growth factor (FGF) signalling is required for effective repression of BMPs and for the acquisition of neural character $[45,46]$. The ectopic expansion of neuroectoderm we observed in our present study is reminiscent of the abnormal expansion of neuroepithelium obtained when BMP activity was blocked with antisense morpholinos in the early amphibian embryo [47]. Neurocan 
has been shown to bind FGFs and could be involved in their sequestration, local retention or presentation to target cells or their receptors $[3,17]$. Earlier studies had indicated the important role of extracellular matrix in the induction of neural-non-neural tissue in the early embryo [48]. In our present work, the abnormal expansion of neuroepithelium could have developed under the influence of the diffuse spread of FGF signals to adjacent cells. It is well known that the ectoderm cells towards the neural boundary that are specified to form epidermis are still labile and have the competence to respond to the neural inducing signals in embryos at stage $\mathrm{HH}$. It would seem that the identity of this developmental field requires safe mechanisms prohibiting the diffuse spread of FGF signals and that neurocan, perhaps in cooperation with other associated molecules, could provide a protective mechanism regulating the diffusion range and the local reception of FGF activity throughout the epiblast. In a succinct review [49], it was pointed out that the ability of proteoglycans to control the distributions of signalling molecules across many cell dimensions is central to patterning tissues.

The cranial neural crest failed to delaminate and migrate when neurocan function was perturbed by the anti-neurocan blocking antibodies (Figures $6 \mathrm{~A}-6 \mathrm{C}$ and $6 \mathrm{~K}-6 \mathrm{M}$ ). The premigratory neural crest formed epithelial pockets located on the apical surface of the ectoderm. The neural crest defects we presented here are remarkably similar to those observed in a previous study using antibodies against tenascin [40]. Bone morphogenetic protein signals, the cooperation of Slug and Rho and a tight regulation of cadherin and N-CAM expression are fundamental for the delamination and emigration of neural crest cells [50]. These findings point to a major role of the neurocan-containing HLT complex in modulating activities of cadherin and N-CAM which are downstream effectors of FGF/BMP signalling and are important for neural crest delamination. Neurocan directly binds tightly to cell-cell adhesion molecules N-CAM and Ng-CAM and blocks adhesion [11,51].

It was also particularly interesting to note that surface ectoderm cells (presumptive epidermis) which are polarized stationary epithelial cells, dissociated from the epithelium, acquired mesenchymal cell migratory properties, transversed basement membranes, invaded into the subectodermal space and interacted with neural tube cells (Figures 6D-6F, 60 and 6P). The epithelial to mesenchymal transition has been associated with the loss of E-cadherin function and the acquisition of migratory properties. Our results indicate that perhaps the antibodies that block a functional site on neurocan disrupted a highly ordered neurocan-containing HLT complex in the subectodermal space that provided an important source of signals and a strict delimitation of the surface ectoderm and neural tube. It is possible that neurocan released from the hyaluronan binding could now bind to its receptor glycosyl transferase (GalNacPTase) on the cell surface and co-ordinately inhibit both cadherin- and $\beta 1$-integrin mediated adhesion as has been described in previous work [13].
An important and challenging area for research is how the different neurocan interactions with growth factors and receptors are modulated in the early embryo development. Developing tissues and organs where novel neurocan patterns have been revealed provide a focus to explore further potential functions of this protein in normal physiology and disease pathogenesis not addressed previously. The amenability of the developing chick to embryo culture offers the possibility to assess directly the neurocan molecular interactions with other extracellular matrix or cell surface molecules and their effect in neural-non-neural cell specification and tissue patterning during organogenesis. The whole embryo culture is a more physiological model system, it allows delicate microsurgical manipulations to be preformed easily, and, in comparison with the culture of dissociated cells, avoids the problems related to the possible removal of signals during the dissociation process.

\section{Conclusions}

In our present study detailing neurocan expression in the very early chick embryo, neurocan was first detected in the inchoate neural plate and the extracellular matrix in embryos at the definitive streak stage (late gastrula). The expression of neurocan was very intense in the neural tube (developing central nervous system). Another significant observation was the very intense expression of neurocan in premigratory and migrating neural crest cells and in mesenchymal tissues known to be derived from the neural crest. Moreover, neurocan was intense in several areas of active cell migration such as the heart, the dispersing somite, the presumptive pronephric tubules and the blood islands.

Inhibition of neurocan function by blocking antibodies resulted in defects in the early embryo consistent with the known biochemical features and interactions of neurocan with signaling molecules: The neural epithelium expanded abnormally in the surface ectoderm (presumptive epidermis) flanking the neural tube showing a change of developmental fate from non-neural to neural possibly because of the diffuse spread of FGF signals. Surface ectoderm cells acquired invasive properties and interacted with the neuroepithelium while cranial neural crest cells formed ectopic aggregates on the apical side of the ectoderm possibly due to perturbation in the tight regulation of cadherin and N-CAM function. Neurocan seems to protect the functional organization of the extracellular matrix and to regulate the diffusion range and the local reception of FGF/BMP signalling activity during the neural-non-neural cell specification. Moreover, neurocan, through its interactions with cell surface molecules, seems to be an extracellular modulator of cell adhesive and signalling activities of epithelial-mesenchymal cells that are central to tissue patterning in the early embryo.

\section{Competing interests}

The authors declare that they have no competing interests. 
Georgadaki et al. Research Journal of Developmental Biology 2014, http://www.hoajonline.com/journals/pdf/2055-4796-1-3.pdf

\section{Authors' contributions}

\begin{tabular}{|l|c|c|}
\hline Authors' contributions & KG & NZ \\
\hline Research concept and design & -- & $\checkmark$ \\
\hline Collection and/or assembly of data & $\checkmark$ & $\checkmark$ \\
\hline Data analysis and interpretation & $\checkmark$ & $\checkmark$ \\
\hline Writing the article & $\checkmark$ & $\checkmark$ \\
\hline Critical revision of the article & -- & $\checkmark$ \\
\hline Final approval of article & $\checkmark$ & $\checkmark$ \\
\hline Statistical analysis & $\checkmark$ & $\checkmark$ \\
\hline
\end{tabular}

\section{Acknowledgement}

We thank the reviewers for their helpful comments. This work was supported by grants from the European Social Fund (ESF), Operational Program for Educational and Vocational Training II (EPEAEK II) particularly the Program "PYTHAGORAS II" and from the University of Patras ("K. Karatheodori" grant B.397).

\section{Publication history}

Senior Editor: Tzi Bun Ng, The Chinese University of Hong Kong, China. Received: 20-Aug-2014 Final Revised: 25-Nov-2014

Accepted: 16-Dec-2014 Published: 22-Dec-2014

\section{References}

1. Margolis RU and Margolis RK. Aggrecan-versican-neurocan family proteoglycans. Methods Enzymol. 1994; 245:105-26. | Article I PubMed

2. Bandtlow CE and Zimmermann DR. Proteoglycans in the developing brain: new conceptual insights for old proteins. Physiol Rev. 2000; 80:1267-90. | Article | PubMed

3. Rauch $U$, Feng $\mathrm{K}$ and Zhou XH. Neurocan: a brain chondroitin sulfate proteoglycan. Cell Mol Life Sci. 2001; 58:1842-56. | Article I PubMed

4. Rauch U, Karthikeyan L, Maurel P, Margolis RU and Margolis RK. Cloning and primary structure of neurocan, a developmentally regulated, aggregating chondroitin sulfate proteoglycan of brain. J Biol Chem. 1992; 267:19536-47. | Article | PubMed

5. Engel M, Maurel P, Margolis RU and Margolis RK. Chondroitin sulfate proteoglycans in the developing central nervous system. I. cellular sites of synthesis of neurocan and phosphacan. J Comp Neurol. 1996; 366:3443. | Article | PubMed

6. Meyer-Puttlitz B, Junker E, Margolis RU and Margolis RK. Chondroitin sulfate proteoglycans in the developing central nervous system. II. Immunocytochemical localization of neurocan and phosphacan. J Comp Neurol. 1996; 366:44-54. | Article I PubMed

7. Balsamo J, Ernst H, Zanin MK, Hoffman S and Lilien J. The interaction of the retina cell surface $\mathrm{N}$-acetylgalactosaminylphosphotransferase with an endogenous proteoglycan ligand results in inhibition of cadherinmediated adhesion. J Cell Biol. 1995; 129:1391-401. | Article | PubMed Abstract I PubMed Full Text

8. Mishima $\mathrm{N}$ and Hoffman $\mathrm{S}$. Neurocan in the embryonic avian heart and vasculature. Anat Rec A Discov Mol Cell Evol Biol. 2003; 272:556-62. | Article I PubMed

9. Oleszewski M, Beer S, Katich S, Geiger C, Zeller Y, Rauch U and Altevogt P. Integrin and neurocan binding to $\mathrm{L} 1$ involves distinct Ig domains. J Biol Chem. 1999; 274:24602-10. | Article | PubMed

10. Harigaya T, Ogawa $H$, Tsunoda $S$ and Nagasawa $H$. The mRNA expression of neurocan, a brain-specific chondroitin sulfate proteoglycan, in neoplastic mammary glands in mice. Zoolog Sci. 1996; 13:665-8. | PubMed

11. Friedlander DR, Milev P, Karthikeyan L, Margolis RK, Margolis RU and Grumet $M$. The neuronal chondroitin sulfate proteoglycan neurocan binds to the neural cell adhesion molecules Ng-CAM/L1/NILE and N-CAM, and inhibits neuronal adhesion and neurite outgrowth. J Cell Biol. 1994; 125:669-80. | Article | PubMed Abstract | PubMed Full Text

12. Milev P, Maurel P, Haering M, Margolis RK and Margolis RU. TAG-1/ axonin-1 is a high-affinity ligand of neurocan, phosphacan/proteintyrosine phosphatase-zeta/beta, and N-CAM. J Biol Chem. 1996; 271:15716-23. | Article | PubMed

13. Li H, Leung TC, Hoffman S, Balsamo J and Lilien J. Coordinate regulation of cadherin and integrin function by the chondroitin sulfate proteoglycan neurocan. J Cell Biol. 2000; 149:1275-88. | Article | PubMed Abstract | PubMed Full Text

14. Arregui C, Pathre P, Lilien J and Balsamo J. The nonreceptor tyrosine kinase fer mediates cross-talk between $\mathrm{N}$-cadherin and beta1-integrins. J Cell Biol. 2000; 149:1263-74. | Article | PubMed Abstract | PubMed Full $\underline{\text { Text }}$

15. Grumet M, Milev P, Sakurai T, Karthikeyan L, Bourdon M, Margolis RK and Margolis RU. Interactions with tenascin and differential effects on cell adhesion of neurocan and phosphacan, two major chondroitin sulfate proteoglycans of nervous tissue. J Biol Chem. 1994; 269:12142-6. | Article | PubMed

16. Milev P, Chiba A, Haering M, Rauvala H, Schachner M, Ranscht B, Margolis RK and Margolis RU. High affinity binding and overlapping localization of neurocan and phosphacan/protein-tyrosine phosphatase-zeta/beta with tenascin-R, amphoterin, and the heparinbinding growth-associated molecule. J Biol Chem. 1998; 273:6998-7005. | Article | PubMed

17. Milev P, Monnerie H, Popp S, Margolis RK and Margolis RU. The core protein of the chondroitin sulfate proteoglycan phosphacan is a high-affinity ligand of fibroblast growth factor-2 and potentiates its mitogenic activity. J Biol Chem. 1998; 273:21439-42. I Article I PubMed

18. Miura R, Aspberg A, Ethell IM, Hagihara K, Schnaar RL, Ruoslahti E and Yamaguchi $Y$. The proteoglycan lectin domain binds sulfated cell surface glycolipids and promotes cell adhesion. J Biol Chem. 1999; 274:11431-8. | Article | PubMed

19. Zhou XH, Brakebusch C, Matthies H, Oohashi T, Hirsch E, Moser M, Krug M, Seidenbecher $\mathrm{Cl}$, Boeckers TM, Rauch U, Buettner R, Gundelfinger ED and Fassler R. Neurocan is dispensable for brain development. Mol Cell Biol. 2001; 21:5970-8. | Article | PubMed Abstract | PubMed Full Text

20. Saga Y, Yagi T, Ikawa Y, Sakakura T and Aizawa S. Mice develop normally without tenascin. Genes Dev. 1992; 6:1821-31. I Article I PubMed

21. Crossin KL. Functional role of cytotactin/tenascin in morphogenesis: a modest proposal. Perspect Dev Neurobiol. 1994; 2:21-32. I PubMed

22. Aszodi A, Legate KR, Nakchbandi I and Faessler R. What mouse mutants teach us about extracellular matrix function. Annu Rev Cell Dev Biol. 2006; 22:591-621. | Article | PubMed

23. Mackie EJ and Tucker RP. The tenascin-C knockout revisited. J Cell Sci. 1999; 112 ( Pt 22):3847-53. | Article I PubMed

24. Jones FS and Jones PL. The tenascin family of ECM glycoproteins: structure, function, and regulation during embryonic development and tissue remodeling. Dev Dyn. 2000; 218:235-59. | Article I PubMed

25. Zimmermann DR and Dours-Zimmermann MT. Extracellular matrix of the central nervous system: from neglect to challenge. Histochem Cell Biol. 2008; 130:635-53. | Article | PubMed

26. Bouvard D, Brakebusch C, Gustafsson E, Aszodi A, Bengtsson T, Berna A and Faessler R. Functional consequences of integrin gene mutations in mice. Circ Res. 2001; 89:211-23. I Article I PubMed

27. Inatani $\mathrm{M}$ and Tanihara H. Proteoglycans in retina. Prog Retin Eye Res. 2002; 21:429-47. I Article I PubMed

28. Hamburger $\mathrm{V}$ and Hamilton HL. A series of normal stages in the development of the chick embryo. J Morphol. 1951; 88:49-92. | Pdf | PubMed

29. Corpuz LM, Dunlevy JR, Hassell JR, Conrad AH and Conrad GW. Molecular cloning and relative tissue expression of decorin and lumican in embryonic quail cornea. Matrix Biol. 2000; 19:699-704. | Article | PubMed

30. Zagris N, Gilipathi K, Soulintzi N and Konstantopoulos K. Decorin developmental expression and function in the early avian embryo. Int $\mathrm{J}$ Dev Biol. 2011; 55:633-9. | Article | PubMed

31. Rauch U, Gao P, Janetzko A, Flaccus A, Hilgenberg L, Tekotte H, Margolis RK and Margolis RU. Isolation and characterization of developmentally regulated chondroitin sulfate and chondroitin/keratan sulfate 
proteoglycans of brain identified with monoclonal antibodies. J Biol Chem. 1991; 266:14785-801. | Article | PubMed

32. Laemmli VK. Cleavage of structural proteins during the assembly of the head of bacteriophage T4. Nature. 1970; 227:680-5. | PubMed

33. New DAT. A new technique for the cultivation of the chick embryo in vitro. J Embryol Exp Morphol 1955; 3:326-331. | Article

34. Humason GL. Animal Tissue Techniques, ed 3. San Francisco: Freeman; 1972.

35. Zagris N, Dimiropoulos A, Konstantopoulos K and Christopoulos M. Integrin $\alpha 6$ during early development of the avian embryo. Trends Dev Biol. 2009; 4:19-32.

36. Le Douarin N. The Neural Crest. Cambridge: Cambridge University Press; 1982.

37. Hall BK. The Neural Crest in Development and Evolution. New York: Springer-Verlag; 1999.

38. Pintar JE. Distribution and synthesis of glycosaminoglycans during quail neural crest morphogenesis. Dev Biol. 1978; 67:444-64. | Article | PubMed

39. Crossin KL, Hoffman S, Grumet M, Thiery JP and Edelman GM. Siterestricted expression of cytotactin during development of the chicken embryo. J Cell Biol. 1986; 102:1917-30. | Article | PubMed Abstract | PubMed Full Text

40. Bronner-Fraser M. Distribution and function of tenascin during cranial neural crest development in the chick. J Neurosci Res. 1988; 21:135-47. | Article | PubMed

41. Harrisson F. The extracellular matrix and cell surface, mediators of cell interactions in chicken gastrulation. Int J Dev Biol. 1989; 33:417-38. I Article | PubMed

42. Perris R, Krotoski D, Lallier T, Domingo C, Sorrell JM and Bronner-Fraser M. Spatial and temporal changes in the distribution of proteoglycans during avian neural crest development. Development. 1991; 111:583-99. | Article | PubMed

43. Rauch U, Clement A, Retzler C, Froehlich L, Faessler R, Goehring W and Faissner A. Mapping of a defined neurocan binding site to distinct domains of tenascin-C. J Biol Chem. 1997; 272:26905-12. | Article | PubMed

44. Yamaguchi Y. Lecticans: organizers of the brain extracellular matrix. Cell Mol Life Sci. 2000; 57:276-89. | Article I PubMed

45. Launay C, Fromentoux V, Shi DL and Boucaut JC. A truncated FGF receptor blocks neural induction by endogenous Xenopus inducers. Development. 1996; 122:869-80. | Article | PubMed

46. Wittler $L$ and Kessel $M$. The acquisition of neural fate in the chick. Mech Dev. 2004; 121:1031-42. | Article | PubMed

47. Reversade B, Kuroda H, Lee H, Mays A and De Robertis EM. Depletion of Bmp2, Bmp4, Bmp7 and Spemann organizer signals induces massive brain formation in Xenopus embryos. Development. 2005; 132:3381-92. | Article | PubMed Abstract | PubMed Full Text

48. Grunz $\mathrm{H}$ and Tacke L. Extracellular matrix components prevent neural differentiation of disaggregated Xenopus ectoderm cells. Cell Differ Dev. 1990; 32:117-23. | Article | PubMed

49. Selleck SB. Proteoglycans and pattern formation: sugar biochemistry meets developmental genetics. Trends Genet. 2000; 16:206-12. | Article | PubMed

50. Knecht AK and Bronner-Fraser M. Induction of the neural crest: a multigene process. Nat Rev Genet. 2002; 3:453-61. | Article I PubMed

51. Retzler C, Goehring W and Rauch U. Analysis of neurocan structures interacting with the neural cell adhesion molecule N-CAM. J Biol Chem. 1996; 271:27304-10. | Article | PubMed

\section{Citation:}

Georgadaki K and Zagris N. Neurocan developmental expression and function during early avian embryogenesis. Res J Dev Biol. 2014; 1:3. http://dx.doi.org/10.7243/2055-4796-1-3 